\title{
10 anos da Política Nacional de Educação Especial em uma perspectiva inclusiva: implicações no Espírito Santo
}

\author{
10 years of National Policy on Special Education in a perspective of \\ inclusive education: implications in Espírito Santo \\ 10 años de la Política Nacional de Educación Especial en una perspectiva \\ inclusiva: implicaciones en Espírito Santo \\ ALEXANDRO BRAGA VIEIRA \\ DENISE MEYRELLES DE JESUS \\ CLAYDE APARECIDA BELO DA SILVA MARIANO \\ LARA REGINA CASSANI LACERDA
}

\begin{abstract}
Resumo: Analisa as implicações da Política Nacional de Educação Especial em uma perspectiva inclusiva, no Espírito Santo. Dialoga com Boaventura de Sousa Santos e se constitui a partir de uma pesquisa qualitativa que recorre a dados de dois estudos: Políticas de Educação Especial no Espírito Santo: implicações para a formação continuada de gestores públicos de Educação Especial (2010-2012) e Observatório Nacional de Educação Especial no Estado do Espírito Santo (2010-2017). No Estado, o referido documento impactou as políticas públicas de Educação Especial e evidenciou desafios no campo do direito à Educação.
\end{abstract}

Palavras-chave: Educação Especial. PNEE/2008. Inclusão Escolar.

Abstract: It analyzes the implications of the National Policy on Special Education from an inclusive perspective, in Espírito Santo. It dialogues with Boaventura de Sousa Santos and is a qualitative research that uses data from two studies: Special Education Policies in Espírito Santo: implications for the continuing education of public administrators of Special Education (2010-2012) and National Observatory of Special Education in the State of Espírito Santo (2012-2017). In the State, this document impacted the public policies of Special Education and highlighted challenges in the field of the right to Education.

Keywords: Special Education. PNEE/2008. School Inclusion.

Resumen: Analiza las implicaciones de la Política Nacional de Educación Especial bajo una perspectiva inclusiva, en Espirito Santo. Dialoga con Boaventura de Sousa Santos y se constituye en una investigación cualitativa que recurre a datos de dos estudios: Políticas de Educação Especial no Espírito Santo: implicações para a formação continuada de gestores públicos de Educação Especial (20102012) y Observatório Nacional de Educação Especial no Estado do Espírito Santo (2012-2017). En el Estado, el referido documento impactó las políticas públicas de Educación Especial y evidenció desafíos en el campo del derecho a la Educación.

Palabras-clave: Educación Especial. PNEE/2008. Inclusión Escolar. 


\section{INTRODUÇÃO}

Elaborada por um Grupo de Trabalho nomeado pela Portaria $\mathrm{n}^{\circ}$. 555/2007 (BRASIL, 2007a), prorrogada pela Portaria n. 948/2007 (BRASIL, 2007b), e entregue ao Ministro da Educação em 07 de janeiro de 2008, a Política Nacional de Educação Especial em uma perspectiva inclusiva apresentou um conjunto de orientações político-pedagógicas direcionadas a subsidiar os processos de escolarização de estudantes com deficiência, transtornos globais do desenvolvimento e altas habilidades superdotação nas escolas de ensino comum.

Encaminhamentos quanto ao público-alvo da Educação Especial, financiamento, perspectiva político-pedagógica do atendimento educacional especializado e formação de professores são alguns elementos que compõem o documento supracitado. Diante da assertiva, o presente texto busca analisar criticamente as implicações que a Política Nacional de Educação Especial em uma perspectiva inclusiva de 2008 trouxe para a escolarização de estudantes com deficiência, transtornos globais do desenvolvimento e altas habilidadessuperdotação em escolas públicas capixabas, sejam elas da Rede Estadual ou municipais de ensino.

Para tais análises, inspiramo-nos em dados produzidos em dois estudos: a) Politicas de Educação Especial no Espirito Santo: implicações para a formação continuada de gestores públicos de Educação Especial (2010-2012); b) Observatório Nacional de Educação Especial no Estado do Espirito Santo (2010-2017). Eles trazem um corpus de conhecimentos que nos ajudam a entender que ações políticas e pedagógicas as redes de ensino (estadual e municipal) passaram a compor para implementar o que foi preconizado pela Política Nacional de Educação Especial em uma perspectiva inclusiva de 2008, salientando os desafios que atravessam o processo.

Organizamos as discussões em três momentos correlacionados. No primeiro, síntese de elementos-chave da Política Nacional de Educação Especial em uma perspectiva inclusiva de 2008 em diálogo com as teorizações de Boaventura de Sousa Santos $(2007,2008)$. Em uma segunda fase, o caminho metodológico para categorização/análise dos dados. Por último, reflexões acerca das implicações do referido documento nas políticas de Educação Especial no contexto capixaba. 


\section{UMA BREVE SÍNTESE DE CONCEITOS-CHAVE DA POLÍTICA NACIONAL DE EDUCAÇÃO ESPECIAL EM UMA PERSPECTIVA INCLUSIVA}

Boaventura de Sousa Santos - teórico português dedicado a estudar a sociologia do conhecimento humano - provoca-nos a pensar o quanto o pensamento moderno se mostra indolente, ou seja, único e totalitário, fazendo com que muitos saberes e experiências (embora existentes) mostrem-se ausentes/ invisíveis no cenário social. É justamente essa compreensão que faz o autor explorar duas abordagens de sociologias.

Trata-se da Sociologia das Ausências e das Emergências, pois, por meio da primeira, pode-se compreender uma inesgotável riqueza de políticas existentes nas sociedades contemporâneas, e, por intermédio da segunda, as ações que podem ser empreendidas para dar visibilidade a toda essa produção, muitas vezes desmerecida pelos cenários sociais.

A ‘sociologia das ausências' visa, essencialmente, [sic] subverter essa produção de
ausências transformando-as em objetos presentes, tornando visível aquilo que vem
sendo escamoteado pela sociologia dominante [...]. A ‘sociologia das emergências'
busca trocar indicadores seguros por pistas incipientes, propondo o "ainda não"
para pensar a realidade como aquilo que não existe mas está emergindo (SOARES,
2007, p. 233).

A linha dorsal da Política Nacional de Educação Especial em uma perspectiva inclusiva de 2008 (BRASIL, 2008) traz elementos que evidenciam os pressupostos da Sociologia das Ausências e das Emergências, pois o texto dá reconhecimento e visibilidade às lutas que se foram constituindo no transcorrer de muitas décadas (por muitos movimentos sociais) para se garantir aos estudantes com deficiência, transtornos globais do desenvolvimento e altas habilidades/ superdotação a defesa do direito de aprender na escola de ensino comum.

No campo teórico, tal Política visibiliza os pressupostos da educação inclusiva, entendida como ação política, cultural, social e pedagógica que referenda o direito de todos à Educação, combatendo qualquer tipo de discriminação e preconceito. Nesse cenário, chama atenção para o papel social da escola: o direito de apropriação do conhecimento, a superação da lógica da exclusão e o combate à naturalização do fracasso escolar (BRASIL, 2008).

Assim, busca inspiração nos pressupostos dos direitos humanos e no reconhecimento das diferenças, compondo problematizações acerca da produção das desigualdades no cenário social e escolar, abrindo reflexões acerca de como a Educação foi subjetivada como direito de poucos e a Educação Especial 
alocada como paralela à Educação regular, situação que levou o atendimento educacional especializado a ser substitutivo ao ensino comum. Evidencia a criação de instituições especializadas, escolas especiais e classes especiais, já que os estudantes não tinham o direito legal de frequentar as escolas comuns.

Essa organização, fundamentada no conceito de normalidade/anormalidade, determina formas de atendimento clínico-terapêuticas fortemente ancorados nos testes psicométricos que, por meio de diagnósticos, definem práticas escolares para estudantes com deficiência (BRASIL, 2008, p. 2).

Para se chegar à compreensão de Educação Especial como modalidade de ensino - não substitutiva ao ensino comum - a Política Nacional de Educação Especial em uma perspectiva inclusiva de 2008 faz um rigoroso resgate educacional histórico, trazendo marcos e legislações que gradativamente foram sustentando a defesa do direito de aprender nas escolas comuns. Se, por um lado, recupera as fragilidades trazidas pela LDB $n^{\circ}$. 4.024/61 e a Lei complementar $n^{\circ} 5.692 / 71$, na organização de um sistema de ensino incapaz de atender aos estudantes nas escolas comuns; de outro lado, evidencia os ganhos trazidos pela Constituição Federal de 1988 ao referendar a Educação como direito de todos e a oferta do atendimento educacional especializado preferencialmente na escola regular de ensino.

Podemos compreender que a Política de Educação Especial de 2008 destaca o quanto o processo de inclusão escolar de estudantes público-alvo da Educação Especial constitui-se pela via de muitos enfrentamentos/lutas sociais, tensionando o fato de a Política Nacional de Educação Especial de 1994 manter "a responsabilidade da educação desses estudantes exclusivamente no âmbito da educação especial” (BRASIL, 2008, p. 3), afastando-os das ações planejadas e praticadas pelos professores do ensino comum.

Por outro lado, reconhece os ganhos trazidos pela Lei de Diretrizes e Bases da Educação nº 9.394/96 no que se refere ao acesso aos currículos, métodos, recursos e organização específicas para atender às necessidades dos alunos, além de terminalidade específica e aceleração de estudos (BRASIL, 1996). Também compõem diálogos com outras normatizações nacionais e documentos internacionais, tendo como base a defesa da aprendizagem na escola comum (com os devidos apoios), destacando um conjunto de ações políticas relevantes para se defender a escola de ensino comum como espaço-tempo de todos.

Outro ponto de análise diz respeito ao diagnóstico da Educação Especial. Podemos entender que a Sociologia das Ausências e das Emergências leva tal documento a evidenciar o processo gradativo de matrícula dos estudantes públicoalvo da Educação Especial nas escolas comuns. Assim, podemos entender: alunos 
com deficiência, transtornos globais do desenvolvimento e altas habilidades/ superdotação fazem parte da escola comum. Desvela que, em 1998, as 337.326 matrículas crescem para 843.342, em 2013, configurando um aumento de $150 \%$, situação que faz emergir um conjunto de políticas públicas educacionais.

Assim, a Política Nacional de Educação Especial em uma perspectiva inclusiva de 2008 traz orientações para os sistemas de ensino visando à inclusão no ensino regular, destacando: direito social à aprendizagem; continuidade nos níveis mais elevados do ensino; transversalidade da modalidade de educação especial desde a Educação Infantil até a Educação Superior; oferta do atendimento educacional especializado; formação de professores tanto para os em atuação nas salas de recursos multifuncionais quanto demais profissionais da educação; participação da família e da comunidade nos processos de escolarização dos alunos; acessibilidade de maneira ampla (arquitetônica, transportes, mobiliários, comunicação, informação e ao conhecimento); e articulação intersetorial na implementação das políticas públicas são alguns eixos tomados como discussão.

Além das questões evidenciadas, traz novas definições para os estudantes público-alvo e para a oferta do atendimento educacional especializado, orientando que a Educação Especial seja assumida como modalidade de ensino. Diante disso, a Educação Especial deve estar integrada à proposta pedagógica da escola, ofertando o atendimento educacional especializado em salas de recursos multifuncionais (no contraturno) como complementar/suplementar ao processo de escolarização dos alunos. Como podemos perceber, a Política Nacional de Educação Especial em uma perspectiva inclusiva de 2008 traz certo corpus histórico, teórico e normativo que sustenta os princípios da inclusão escolar, defendendo o direito de todos aos conhecimentos historicamente acumulados e a serem mediados nos ambientes escolares.

\section{A METODOLOGIA ADOTADA PARA A REALIZAÇÃO DO ESTUDO}

O estudo tem o objetivo de analisar criticamente as implicações que a Política Nacional de Educação Especial em uma perspectiva inclusiva de 2008 trouxe para os processos de escolarização de estudantes público-alvo da Educação Especial no Estado do Espírito Santo. Pauta-se em dados coletados na pesquisa Políticas de Educação Especial no Espirito Santo: implicações para a formação continuada de gestores públicos de Educação Especial, realizada nos anos de 2010 a 2012, envolvendo 104 profissionais ligados à gestão da Educação Especial, representando os 
78 municípios que compõem o Estado do Espírito Santo. Esses profissionais participaram de uma pesquisa-formação de 200 horas, com 96 horas presenciais e 104 não presenciais.

Outro estudo é denominado Observatório Nacional de Educação Especial: um estudo em rede nacional sobre o funcionamento das salas de recursos multifuncionais, realizado nos anos de 2010 a 2017. No Espírito Santo, a investigação deu-se em dois momentos. Em um primeiro momento, a coleta de narrativas de professores sobre: a) a formação inicial e continuada; b) avaliação diagnóstica e de rendimento escolar dos alunos; c) o trabalho com o atendimento educacional especializado. Essa etapa envolveu 139 professores de Educação Especial em atuação em dez redes de ensino capixabas. Em uma segunda fase, 52 professores participaram da composição de uma pesquisa/formação para discussão de questões que desafiavam a Educação Especial na escola comum.

Foram lidos os relatórios de pesquisa e elencadas as discussões que tratavam das seguintes temáticas: a) a formação docente; b) os sujeitos públicoalvo; c) o atendimento educacional especializado; d) o financiamento da Educação Especial. Os dois estudos trabalharam com grupos focais, sendo utilizados a videogravação e diários reflexivos.

\section{AS IMPLICAÇÕES DA PNEE/2008 NAS POLÍTICAS DE EDUCAÇÃO ESPECIAL NO ESPÍRITO SANTO}

Um primeiro eixo de discussão refere-se à formação de professores para realização do atendimento educacional especializado. Podemos perceber que as redes públicas de ensino (estadual e municipais) também encontraram na Política Nacional de Educação Especial em uma perspectiva inclusiva de 2008 impulsos para fomentar políticas de formação continuada, tendo em vista a necessidade de compreender as funções das salas de recursos multifuncionais e do atendimento educacional especializado como complementar/suplementar aos currículos escolares.

Mesmo, muitos professores possuindo cursos de graduação, especialização e de capacitação em Educação Especial, outras possibilidades de formação emergiram. Uma delas, foi o envolvimento dos professores no Curso de Especialização em Atendimento Educacional Especializado, ofertado pelo Ministério da Educação, em parceria com instituições públicas de ensino superior. 
Os professores têm participado da pós em AEE, ofertado pelo MEC (PARTICIPANTE DO ONEESP).

Na pós-graduação em AEE, os professores têm feito discussões sobre o que vem a ser o complementar/suplementar na escolarização dos alunos, sobre as atribuições dos professores especializados e a perspectiva teórica defendida pelo MEC sobre o AEE (PARTICIPANTE DO CURSO DE GESTORES).

$\mathrm{Na}$ especialização, os professores vivenciaram experiências diferenciadas de formação. A maior parte realizou via pressupostos da Educação a distância. Houve também a oferta de curso presencial. Nos cursos a distância, os currículos mostravam-se mais fechados. Na proposta presencial, o currículo foi composto em consonância com os professores que ministraram as disciplinas, a coordenação do curso e os cursistas.

$\mathrm{Na}$ análise dos professores, muitas instituições não trataram de todas as áreas que compõem a Educação Especial e algumas deram maior destaque às dificuldades dos processos de escolarização dos alunos em detrimento das possibilidades de trabalho pedagógico. Outras abordaram os desafios atrelados a possíveis alternativas de trabalho docente. Mesmo com essa diversidade de questões, um elemento transversalizou o Curso de Especialização em Atendimento Educacional Especializado: ele trouxe reflexões sobre os pressupostos teóricos/ legais que subsidiam a oferta do AEE como complementar/suplementar aos processos de escolarização dos estudantes nas escolas de ensino comum, bem como a necessária articulação entre professores de Educação Especial e os de sala de aula.

Fizemos o Curso de Pós-Graduação em AEE. O curso era um pouco fechado, porque era a distância. A tutora não tinha como mudar o que já estava proposto na plataforma. Mesmo assim, deu para entender um pouco mais sobre o trabalho no AEE (PARTICIPANTE DO ONEESP).

Senti falta das Altas Habilidades. O Curso focou mais as dificuldades dos alunos e o que a escola não fazia (PARTICIPANTE DO CURSO DE GESTORES).

O Curso nos ajudou muito. Tivemos a oportunidade de estudar várias questões da Educação Especial. O Curso foi presencial. Tivemos aulas sobre o AEE. Lemos textos e debatemos. Para mim, foi muito bom (PARTICIPANTE DO ONEESP).

As narrativas nos fazem recorrer a Pimenta (2005) quando problematiza que na formação de professores há de se pensar em estratégias para formar sujeitos que se assumem produtores de conhecimento, pesquisadores de novos/ outros saberes e profissionais capazes de mediar a aprendizagem humana, pois os desafios da prática são reais e constituídos cotidianamente nas escolas, 
demandando enfrentamentos propositivos mediados pela constituição de subjetividades rebeldes ${ }^{1}$ (SANTOS, 2006) para transformá-los em novas lógicas de ensino-aprendizagem.

As experiências vividas pelos professores nos Cursos de Especialização nos fazem pensar na necessidade do fomento de formação que postulem pela inseparável relação teoria e prática. Os Cursos de Especialização em AEE (mesmo com algumas fragilidades) abriram caminhos para os professores ampliarem seus saberes-fazeres sobre o atendimento às especificidades dos alunos a partir da proposição trazida pela Política Nacional de Educação Especial em uma perspectiva inclusiva de 2008.

As redes de ensino também ganharam outros impulsos para fomentar suas próprias políticas de formação continuada. Parcerias com instituições de ensino superior, participação em eventos (seminários e colóquios) e a promoção de encontros/cursos de capacitação buscaram ajudar os docentes a compreender as orientações trazidas pelo documento em questão e subsequentes (Resolução 4/2009 e Decreto 7.611/2011) sobre os direcionamentos a serem adotados pela Educação Especial. Ganham ênfase discussões sobre o público-alvo da modalidade de ensino; a orientação pedagógica e normativa para a oferta do AEE; o acesso aos currículos escolares; a parceria entre os profissionais da Educação; e a composição de Planos de Atendimento Educacional Especializado.

O município vem fazendo formação com os professores. Questões novas, como os alunos atendidos e o AEE tem sido alguns temas das formações (PARTICIPANTE DO ONEESP).

Com o Curso de Gestores em Educação Especial, tínhamos como tarefa organizar um Plano de Trabalho. O nosso foi para pensar a formação continuada. Fizemos parcerias com mestrandos e doutorandos da UFES e montamos um curso. Convidamos professores da Rede Estadual também. Os professores puderam refletir sobre a Educação Especial e o AEE (PARTICIPANTE CURSO DE GESTORES).

A gente tenta fazer essas capacitações internamente, utilizando recursos que a gente tem disponível. Quando isso acontece, pouco importa se é profissional da APAE ou profissional da SEDU que está atendendo a nossa clientela. Então, todos são formados, mas tem a dificuldade de fazer com mais afinco em virtude dos recursos (PARTICIPANTE CURSO DE GESTORES).

1 Santos (2006) denomina subjetividades rebeldes, pensamentos e ações compromissados com a constituição de uma sociedade mais inclusiva e respeitosa à diversidade/diferença humana. 
Outras composições de formação foram sistematizadas e essa situação nos faz recordar Nóvoa (1992), quando diz sobre a importância de se diversificarem os modelos de formação de professores, tendo em vista uma única abordagem se asfixiar e se tornar insatisfatória. Tal ação é prevista na LDB nº 9.394/96 e, como afirma Pimenta (2005), cabe às redes de ensino mobilizar os saberes da experiência, os saberes pedagógicos e os saberes científicos, alocando-os como constitutivos da docência e da identidade profissional dos professores.

Outra possibilidade de formação continuada foi o desenvolvimento de trabalhos colaborativos entre professores do ensino comum e os do atendimento educacional especializado. Muitas redes de ensino já buscavam respaldo em estudos que entendem o quanto essa articulação se coloca como uma estratégia para se potencializarem os processos de ensino-aprendizagem e as políticas de formação continuada de professores (MENDES; VIRALONGA; ZERBATO, 2014).

Em nossa escola estamos vivendo questões que têm desestabilizado e angustiado os professores em seus fazeres. Muitas angústias são divididas pelos professores com seus pares em torno das impossibilidades vividas no cotidiano da escola, impossibilidades que giram em torno da gestão escolar e interferem sobremaneira nos fazeres pedagógicos. Em meio a essas angústias levantamos a importância de articularmos ações e pensamentos dos diferentes profissionais para modificarmos a realidade abrindo-se assim múltiplas possibilidades (PARTICIPANTE ONEESP).

Com o Curso de Gestores, o debate sobre o trabalho colaborativo nos ajudou a entender que nele é possível pensar a formação continuada. A troca, a reflexão e o trabalho coletivo é uma estratégia de formação continuada (PARTICIPANTE CURSO DE GESTORES).

O trabalho colaborativo possibilita a tradução² (SANTOS, 2007) entre teoria e prática e aproxima os saberes-fazeres dos vários profissionais da escola, bem como do currículo da sala de aula comum com as ações do atendimento educacional especializado. As redes de ensino capixaba vêm apostando em tal estratégia formativa, principalmente quando a Política Nacional de Educação Especial em uma perspectiva inclusiva de 2008 convoca o trabalho com o AEE como complementar/suplementar à escolarização dos alunos.

Um segundo elemento que sofreu impacto da citada Política foi a definição de alunos apoiados pela Educação Especial. A tendência capixaba seguia a moda nacional. Desde a década de 1990, adotava o conceito de estudantes com necessidades educacionais especiais. Tal conceito mostrava-se muito amplo, 
levando as unidades de ensino a encaminhar todos os alunos que traziam trajetórias mais diferenciadas de aprendizagem para a Educação Especial, como podemos perceber nos excertos que seguem.

Quando era necessidade educacional especial o grupo de atendimento era mais amplo, mas agora a coisa ficou mais restrita (PARTICIPANTE DO CURSO DE GESTORES).

Com a nova Política de Educação Especial, agora, não se trabalha mais com os alunos com necessidades educacionais especiais. Era esse o termo que a gente usava antigamente. Agora são alunos com deficiência, transtornos globais do desenvolvimento e altas habilidades-superdotação. Só que isso aguçou a coisa do laudo. Para dizer que tem deficiência, a escola cobra o laudo (PARTICIPANTE DO ONEESP).

O laudo passou a ser o instrumento mais cobrado pela escola para o aluno ser atendido no AEE. Agora nós só atendemos os alunos com deficiência, transtornos globais e altas habilidades. Antes eram os alunos com necessidades educacionais especiais. Mas, o que fazer com os alunos com hiperatividade, déficit de atenção, dislexia, por exemplo? Eles não podem ser atendidos, mas quem vai dar conta desse grupo? (PARTICIPANTE DO CURSO DE GESTORES).

Com a Política Nacional de Educação Especial em uma perspectiva inclusiva de 2008, definiu-se como público-alvo os estudantes com deficiência, transtornos globais do desenvolvimento e altas habilidades superdotação, restringindo um pouco mais o grupo de estudantes outrora atendido. Para os demais grupos de estudantes, como os casos de estudantes com "transtornos funcionais específicos, a educação especial atua de forma articulada com o ensino comum, orientando para o atendimento desses estudantes" (BRASIL, 2008, p. 11).

Esse direcionamento colaborou com discussões sobre os impactos que o conceito necessidades educacionais especiais trazia para a produção da deficiência socialmente constituída. Esse debate leva-nos a pensar no quanto as escolas ainda ressentem da necessidade dos diagnósticos clínicos para encaminhamento dos alunos aos serviços de apoio, fazendo emergir a necessária continuidade dos investimentos na formação docente para fortalecimento do direito de aprender dos alunos, bem como de outras políticas para atendimento aos estudantes que apresentam necessidades educacionais especiais não vinculadas às deficiências, transtornos globais do desenvolvimento e altas habilidades/superdotação. 
Geralmente eles pedem ao professor especialista para fazer uma avaliação diagnóstica inicial e aí a gente traz para mais perto da gente nas salas de recursos [...]. Faz-se um relato pedagógico, uma avaliação pedagógica [...] através da análise de outros relatórios também. Caso o aluno apresente na avaliação limitações muito severas, tanto de comportamento quanto de aprendizagem [...], é indicada a necessidade de avaliação médica, dos especialistas - neurologistas psicólogos - para diagnóstico com CID, para matrícula no AEE (PARTICIPANTE DO ONEESP).

Então, muitas vezes nos deparamos com a família, mas ela não foi atrás do laudo. Aí você pega a pasta da criança e vê que há não sei quantos anos o laudo já foi pedido [...]. Encaminhando para o posto de saúde, porque agora ficou mais difícil. Antes a gente encaminhava para a APAE, pelo menos em dois meses já tinha o retorno. Agora passa o ano inteiro esperando o retorno (PARTICIPANTE DO ONEESP).

Mesmo com vários estudos no campo da Educação Especial sinalizando que muitos diagnósticos clínicos são amplamente questionáveis e que é preciso colocar em análise a produção social da deficiência, encontramos unidades de ensino que ainda constituem uma relação de dependência para com os laudos médicos para a realização do trabalho pedagógico realizado com alunos diversos, como salienta Bueno (2008), em suas teorizações.

As definições políticas e pedagógicas acerca do atendimento educacional especializado também sofreram influencias da Política Nacional de Educação Especial em uma perspectiva inclusiva de 2008. Kassar e Rabello (2013) problematizam que, desde a década de 1970, encaminhamentos foram adotados para atendimentos específicos às aprendizagens dos alunos. Já nessa época, assumiam-se os atendimentos de natureza médico-psicossocial em primazia dos pedagógicos. Eram as atividades de atendimento especializado, as responsáveis pela escolarização dos alunos e não as ações planejadas e desenvolvidas pela escola (KASSAR; REBELLO, 2013).

Com a Constituição Federal de 1988 (BRASIL, 1988) e a Lei de Diretrizes e Bases da Educação Nacional n. 9.394/96 (BRASIL, 1996), foi definido que os alunos público-alvo da Educação Especial teriam o direito de oferta do atendimento educacional especializado preferencialmente na rede regular do ensino. No entanto, a pergunta que emergiu foi: o "preferencialmente" se reporta à matrícula na escola comum ou nas instituições especializadas? Qual a vertente política e pedagógica do AEE? O que seria o AEE? Com o Programa Educação Direito à Diversidade e a Política Nacional de Educação Especial em uma perspectiva inclusiva (BRASIL, 2008) e documentos subjacentes - Decreto n ${ }^{\circ}$ 7.611/2011 (BRASIL, 2011) e Resolução no 4/2009 (BRASIL, 2009) - orientações acerca da oferta do atendimento educacional especializado ganharam maior ênfase nas pautas da Educação Especial. 
Os sistemas de ensino devem matricular os estudantes com deficiência, transtornos globais do desenvolvimento e altas habilidades/superdotação nas classes comuns do ensino regular e no Atendimento Educacional Especializado - AEE, complementar ou suplementar à escolarização, ofertado em salas de recursos multifuncionais ou em centros de AEE da rede pública ou de instituições comunitárias, confessionais ou filantrópicas sem fins lucrativos (BRASIL, 2008, p. 6, grifos nossos).

Esse ordenamento ganhou diferentes relevos nas políticas de Educação Especial no contexto capixaba. A maioria das redes de ensino seguiu a orientação nacional e alocou a oferta de tais serviços nas salas de recursos multifuncionais. Com isso, emerge a sistematização de Planos de Atendimentos Individualizados. Outras redes de ensino já acumulavam a experiência com atendimentos no contraturno (como apoio ao horário regular) e já tinham rompido com tal perspectiva, alocando os professores em trabalhos colaborativos nas salas de aula comum. Mesmo assim, retomaram essa decisão e passaram a trabalhar com um duplo modo de operacionalizar o atendimento educacional especializado: no contraturno (em salas de recursos multifuncionais) e no turno regular (via ações de colaboração entre professores de ensino comum e de Educação Especial). Nesse caso, o professor especializado acumulou essa dupla incumbência.

$\mathrm{Na}$ rede estadual, os professores têm 25 horas de trabalho no AEE. Uma parte é para o atendimento no contraturno; outra para planejamento e uma para o trabalho colaborativo (PARTICIPANTE DO CURSO DE GESTORES).

Lá na prefeitura, o AEE é feito nas salas de recursos multifuncionais, no contraturno. O professor de Educação Especial organiza o PEI e a partir deles os trabalhos são realizados (PARTICIPANTE DO ONEESSP).

Na nossa rede municipal, foi priorizado o trabalho colaborativo, mas o professor também tem que fazer o AEE no contraturno. Priorizou o colaborativo, porque os alunos têm dificuldade de voltar no outro turno (PARTICIPANTE DO ONEESP).

Os desafios de se pensar o atendimento educacional especializado como complementar/suplementar colocou um desafio. Isso levou outras redes de ensino a compor dois tipos de trabalho: o professor colaborador das ações inclusivas e o professor do atendimento educacional especializado. O primeiro presta apoio no horário de aula regular e o segundo realiza intervenções mais específicas no contraturno, atendendo, inclusive, estudantes de escolas circunvizinhas.

Temos dois tipos de professores. O professor colaborador das ações inclusivas atua no horário de aula regular e desenvolve trabalhos colaborativos com os professores regentes. Os professores do AEE são os do contraturno, atuam nas salas de recursos multifuncionais e atendem os alunos individuais ou em grupos (PARTICIPANTE DO CURSO DE GESTORES). 
Antes mesmo da Política Nacional de Educação Especial em uma perspectiva inclusiva de 2008, a contratação de estagiários já se configurava como uma política recorrente na escolarização dos alunos. Tais contratações somadas a de cuidadores como apoio pedagógico colocam-se como desafios para o atendimento às especificidades dos alunos e para a oferta do AEE, mesmo o documento supracitado sinalizando que os cuidadores devem desempenhar ações de apoio na alimentação, higienização e locomoção dos estudantes.

$\mathrm{Na}$ rede, os estagiários também apoiam os alunos. É um desafio, pois para muitas escolas, se não vai o estagiário, a criança não pode frequentar a escola (PARTICIPANTE DO CURSO DE GESTORES).

Muitas escolas pedem os estagiários, antes mesmo de conhecer o aluno. Se a família diz que o aluno é especial, a escola já quer o estagiário (PARTICIPANTE DO CURSO DE GESTORES).

Tem escolas que preferem os estagiários aos professores. Pode até faltar o professor, mas nunca o estagiário (PARTICIPANTE DO CURSO DE GESTORES).

O problema agora são os cuidadores. A família cobra e a escola também. Não importa a condição da criança, mas a rede tem que mandar o cuidador. É preciso definir a função e a formação desse profissional (PARTICIPANTE DO ONEESP).

Podemos compreender que no Estado do Espírito Santo há um mosaico de possibilidades de se pensar o atendimento educacional especializado, fazendo emergir a necessidade de se tensionar o quanto essas redes vêm-se colocando como ação complementar/suplementar para acesso aos currículos escolares.

Embora a Política Nacional de Educação Especial em uma perspectiva inclusiva de 2008 sinalize que o AEE deva ser realizado no contraturno e em salas de recursos multifuncionais, concordamos com Baptista (2011), quando argumenta que tais atendimentos devam ser multifuncionais para apoiar as ações planejadas e desenvolvidas pelos professores. O Estado do Espírito Santo tem buscado alternativas para além do proposto pela referida Política, fazendo evidenciar novas-outras possibilidades.

Por último, um grande impacto trazido pela Política Nacional de Educação Especial em uma perspectiva inclusiva de 2008 diz respeito ao financiamento da Educação Especial. Segundo o Art. 9-A, do Decreto n ${ }^{\circ} 7.611 / 2011$ e $\int 1^{\circ}$ (BRASIL. 2011), para efeito da distribuição dos recursos do FUNDEB, será admitida "a dupla matrícula dos estudantes da educação regular da rede pública que recebem atendimento educacional especializado. A dupla matrícula implica o cômputo do estudante tanto na educação regular da rede pública, quanto no atendimento educacional especializado". 
O Estado do Espírito Santo é o único ente federado que conta com um terceiro financiamento em Educação Especial na oferta do atendimento educacional especializado. A Secretaria de Estado da Educação (SEDU), por meio de um Termo de Cooperação Técnica, assinado com as Secretarias Municipais de Educação, compromete-se a custear os atendimentos realizados nos Centros de Atendimento Educacional Especializado para alunos da rede estadual e municipais, mesmo que os discentes frequentem as salas de recursos multifuncionais (de sua escola ou de outra unidade de ensino). Tal questão evidencia a forte tendência da relação público-privado, pois, em meio a correlações de forças, o Estado do Espírito Santo continua investindo nas instituições filantrópicas com recursos que deveriam ser destinados à melhoria das unidades públicas de ensino.

\begin{abstract}
A Secretaria de Estado da Educação, órgão proponente signatário do credenciamento, propõe o credenciamento de instituições comunitárias, confessionais ou filantrópicas sem fins lucrativos para Atendimento Educacional Especializado no contraturno do ensino regular aos alunos da rede estadual e municipal que apresentam deficiência, nos diversos municípios no Estado do Espírito Santo. Cabe registrar, que para o atendimento aos alunos das redes municipais será necessário que o município tenha aderido ao Convênio de Cooperação Técnica proposto pelo Estado do Espírito Santo para melhoria das condições de atendimento dos alunos público-alvo da Educação Especial (ESPÍRITO SANTO, 2014, p. 09).
\end{abstract}

Por longos anos, a Secretaria de Estado da Educação do Espírito Santo promoveu a cessão de profissionais para as instituições especializadas. Com o Termo de Cooperação Técnica, as instituições especializadas vêm compondo editais para contratação de profissionais com recursos advindos do poder público estadual (professores e equipe técnica).

A criança agora pode fazer o AEE tanto na escola quanto na APAE. Quando é feito também na APAE é o Estado que paga. Os municípios assinaram um Termo de Cooperação Técnica (PARTICIPANTE DO CURSO DE GESTORES).

Temos orientado aqueles casos que precisam de serviços na área da saúde que também façam o AEE na APAE, já que o município assinou o Termo de Cooperação Técnica (PARTICIPANTE DO ONEESP).

Se, por certo tempo, o Termo de Cooperação Técnica permitia que os estudantes pudessem participar do atendimento educacional especializado ofertado nas salas de recursos multifuncionais e nos Centros de AEE (em virtude do triplo financiamento capixaba), agora, os referidos centros convocam as famílias a realizar “escolhas”: ou lá (SRM) ou cá (no CAEE). 
Os repasses diminuem. As instituições sinalizam a importância de serviços clínicos e terapêuticos (ofertados nos CAEEs) em detrimento dos pedagógicos realizados nas salas de recursos. A fragilidade dos equipamentos públicos estaduais e municipais na área da saúde e assistência social corrobora o processo. Com isso, desvela-se (mais uma vez) a primazia do clínico sobre o pedagógico.

Percebemos que, não diferente de outros Estados brasileiros, a filantropia e a relação público-privado são questões ainda presentes na Educação. Como afirma Peroni (2009), quando olhamos a Educação Especial, vemos o poder público fazendo da prática de repasses de recursos públicos às instituições não governamentais uma possibilidade de elas executarem tarefas que seriam do poder público. Com isso, retira ou diminui a ação do Estado na execução de políticas, passando-as para a sociedade civil.

\section{CONSIDERAÇÕES FINAIS}

A Política Nacional de Educação Especial em uma perspectiva inclusiva de 2008 evidenciou um conjunto de fatos históricos, normativos e teóricos que se foram constituindo para adensar as lutas firmadas pelos movimentos sociais para inclusão dos estudantes com deficiência, transtornos globais do desenvolvimento e altas habilidades/superdotação nas escolas comuns. Podemos dizer que, por meio da Sociologia das Ausências e das Emergências, essa processualidade histórica foi se constituindo.

Também podemos inferir que tal Política trouxe movimentos para a Educação Especial no Estado do Espírito Santo, levando muitas redes de ensino a fortalecer propostas de formação continuada, bem como compor arranjos para a oferta do atendimento educacional especializado. Quando olhamos o públicoalvo atendido pela modalidade, podemos dizer que vivemos um grande desafio: pensar em outras redes de apoio para além daquelas destinadas aos estudantes apoiados pela Educação Especial. O campo do financiamento também demonstra grandes desafios, principalmente quando atravessado pela relação público-privado, colocando em uma linha tênue o trabalho a ser realizado nas salas de recursos multifuncionais e nas salas de aulas comuns.

Entre desafios e processualidade, a Educação Especial no Espírito Santo vai-se constituindo como modalidade de ensino, buscando fortalecer o direito de aprender dos alunos e a necessária formação dos professores, pois como alerta Santos (2006): há de se comporem alternativas para se promover uma maior justiça social e cognitiva, eixos centrais de sistemas de ensino que se buscam assumir mais inclusivos. 


\section{REFERÊNCIAS}

BAPTISTA, Claudio Roberto. Ação pedagógica e educação especial: a sala de recursos como prioridade na oferta de serviços especializados. Revista Brasileira de Educação Especial, Marília, v. 17, n. 1, mai./Ago. 2011.

BRASIL, Ministério da Educação. Decreto 7611, de 17 de novembro de 2011. Dispõe sobre a educação especial, o atendimento educacional especializado e dá outras providências. Disponível em: <http://portal.mec. gov.br/dmdocuments/rceb004_09.pdf>. Acesso em: 10 mar. 2014.

BRASIL. Ministério da Educação. Portaria n 555/2007. Diário Oficial da União, Brasília, 06 jun. 2007. Seção 2, p. 9. 2007a.

BRASIL. Ministério da Educação. Portaria n 948/2007. Diário Oficial da União, Brasília, 09 out. 2007. Seção 2, p. 10. 2007b.

BRASIL. Lei $\mathrm{n}^{\circ}$ 9.394, de 20 de dezembro de 1996. Estabelece as diretrizes e bases da educação nacional. Diário Oficial [da] República Federativa do Brasil, Brasília, 23 de dez. 1996. Seção 1.

BRASIL. Constituição [da] República Federativa do Brasil. Brasília: Senado Federal, 1988.

BRASIL, Ministério da Educação. Política pública de educação especial na perspectiva da educação inclusiva, 2008. Disponível em: $<$ http://portal.mec. gov.br/arquivos/pdf/politicaeducespecial.pdf>. Acesso em: 10 fev. 2019.

BRASIL. Decreto n. 7.611. Dispõe sobre a educação especial, o atendimento educacional especializado e dá outras providências. Diário Oficial [da] República Federativa do Brasil, Brasília, 17 de nov. 2011.

BRASIL. Resolução CNE/CEB $n^{\circ}$. 4. Institui diretrizes nacionais para o atendimento educacional especializado na educação básica, modalidade educação especial. Diário Oficial [da] República Federativa do Brasil, Brasília, 2 de out. 2009. Seção 1. 
BUENO, José Geraldo Silveira. As políticas de inclusão escolar: uma perspectiva de educação especial?. In: BUENO, José Geraldo Silveira; MENDES, Giovana Mendonça Lunardi; SANTOS, Roseli Albino dos (Org.). Deficiência e escolarização: novas perspectivas de análise. Araraquara, SP: Junqueira \& Marin, 2008. p. 43-63.

ESPÍRITO SANTO. Edital de Credenciamento $\mathbf{N}^{\circ}$ 001/2014. Dispõe do credenciamento de instituições comunitárias, confessionais ou filantrópicas sem fins lucrativos para atendimento educacional especializado no contraturno do ensino regular aos alunos da rede estadual e municipal que apresentam deficiência e/ou transtornos globais de desenvolvimento, nos Municípios do 140 Estado do Espírito Santo. Vitória-ES, 2014 Disponível em www.apaees.org.br/anexo. phtml/4024. Acesso em 18 jul. 2014.

JESUS, Denise Meyrelles de. Políticas de Educação Especial no Espírito Santo: implicações para a formação continuada de gestores públicos de Educação Especial. Projeto de Pesquisa - Formação de Gestores em Educação Especial, Convênio UFES/SEDU. Vitória, ES, 2010.

KASSAR, Mônica de Carvalho Magalhães; REBELO, Andressa Santos. O "Especial na educação, o atendimento educacional especializado e a educação especial. In: JESUS, Denise Meyrelles de; BAPTISTA, Claudio Roberto; CAIADO, Katia Regina Moreno (Org.). Prática pedagógica na educação especial: multiplicidade do atendimento educacional especializado. Araraquara, São Paulo: Junqueira Marin, 2013. p. 21-42.

MENDES, Enicéia Gonçalves. Observatório Nacional de Educação Especial: estudo em rede nacional sobre as salas de recursos multifuncionais nas escolas comuns. Projeto de Pesquisa - Observatório da Educação, edital No 38/2010 CAPES/INEP. Brasília, DF, 2010.

MENDES, Eniceia Gonçalves; VIRALONGA, Carla Ariela Rios; ZERBATO, Ana Paula. Ensino colaborativo como apoio à inclusão escolar: unindo esforços entre a educação comum e a especial. Revista Brasileira de Estudos Pedagógicos (online), Brasília, v. 95, n. 239, p. 139-151, jan./abr. 2014.

NÓVOA, Antonio (Org.). Os professores e sua formação. Lisboa: Nova Enciclopédia, 1992. 
PERONI, Vera. Políticas educacionais e a relação público/privado. In: $32^{\mathbf{a}}$ Reunião Anual da ANPEd. Caxambu, MG, 2009.

PIMENTA, Selma Garrido. Professor reflexivo: construindo uma crítica In: PIMENTA, Selma Garrido; GHEDIN, Evandro (Org.). Professor reflexivo no Brasil: gênese e crítica de um conceito. São Paulo: Cortez, 2005. p. 17-52.

SANTOS, Boaventura de Sousa. A gramática do tempo: para uma nova cultura política. São Paulo: Editora Cortez, 2006.

SANTOS, Boaventura de Sousa. Renovar a teoria crítica e reinventar a emancipação social. São Paulo: Boitempo, 2007.

SANTOS, Boaventura de Sousa. A filosofia à venda, a douta ignorância e a aposta de Pascal. Revista crítica de ciências sociais, Coimbra, Portugal, n. 80, p. 1143, mar. 2008.

SOARES, Rosana de Lima. Ausências e emergências: produção do conhecimento e transformação social - Revista Matrizes (resenha). São Paulo (SP): ECA-USP, p. 231-235, 2007.

ALEXANDRO BRAGA VIEIRA possui graduação em Letras e Pedagogia, Mestrado, Doutorado e Pós-Doutorado pela Ufes. Professor do Centro de Educação da Ufes. Professor do Programa de Pós-Graduação de Mestrado em Ensino, Educação Básica e Formação de Professores - Ufes - Alegre. Coordenador do Programa de Pós-Graduação de Mestrado Profissional em Educação - Ufes. Areas de Pesquisa: Educação Especial: formação docente, políticas públicas e currículos. E-mail: allexbraga@hotmail.com

DENISE MEYRELLES DE JESUS possui graduação em Pedagogia, Mestrado e Doutorado - Estados Unidos. Pós-Doutorado em Educação - USP. PósDoutorado em Educação-UFGRS.É professora do Programa de Pós-Graduação em Educação - Ufes. Areas de Pesquisa: Educação Especial: formação docente e políticas públicas educacionais inclusivas. E-mail: jesusdenise@hotmail.com 
CLAYDE APARECIDA BELO DA SILVA MARIANO possui graduação em Pedagogia, mestrado em Ensino, Educação Básica e Formação de Professores. É professora da Rede Municipal de Ensino de Cachoeiro de Itapemirim - ES. Áreas de Pesquisa: Educação Especial, formação docente e práticas inclusivas. E-mail: claydeaparecidabelomariano@gmail.com

LARA REGINA CASSANI LACERDA possui graduação em Educação Física e Pedagogia. Mestranda do Programa de Pós-Graduação de Mestrado Profissional em Educação - Ufes. Professora da Rede Estadual de Ensino do Espírito Santo. Área de estudos: Educação Especial - formação docente, políticas, práticas educativas e educação de surdos. E-mail: laralacerda1@yahoo.com.br

Recebido em setembro de 2018 Aprovado em janeiro de 2019 